\title{
Kinetic Study of Saponin Extraction from Sapindus rarak DC by Ultrasound-Assisted Extraction Methods
}

\author{
Aininu Nafiunisa, Nita Aryanti*, Dyah Hesti Wardhani \\ Department of Chemical Engineering, Faculty of Engineering, Diponegoro University, \\ Jl. Prof. Soedarto, Kampus Undip Tembalang, Semarang Indonesia
}

Received: 25th January 2019; Revised: $9^{\text {th }}$ May 2019; Accepted: $9^{\text {th }}$ May 2019;

Available online: 10th May 2019; Published regularly: 1st August 2019

\begin{abstract}
Saponin is an important plant-derived compound that is commonly found in sapindaceae plants, such as Sapindus rarak DC. Saponin is extensively used in plenty of industries as a detergent or emulsifying agent in cleansers, shampoos, and cosmetics. The extraction of saponin was previously studied and shows that the extraction assisted by ultrasonic waves was found to be an effective method. However, the previous studies have rarely examined the extraction kinetic study of the ultrasound-assisted extraction (UAE). In the present study, the extraction of saponin from Sapindus rarak DC and its extraction kinetics is conducted. The results show that the highest saponin yield of $354.92(\mathrm{mg}$ of saponin per gram of dry feed) was obtained from the extraction using a solid-to-liquid (S/L) ratio of 1:50 (w/v) at 50 ${ }^{\circ} \mathrm{C}$. The amount of extracted saponin increased with the increase of extraction temperature as well as the solute ratio in the solution. However, increasing the temperature to $60{ }^{\circ} \mathrm{C}$ decreased the saponin yield. The results of a simple kinetics study of saponin extraction also show that the second-order kinetics model can better describe the UAE process, with an $\mathrm{R}^{2}$ value of 0.929 and a rate coefficient of $0.00495 \mathrm{~L}^{-\mathrm{g}^{-1}} \cdot \mathrm{min}^{-1}$. The experimental results agree well with the practical calculations obtained using the second-order kinetics model based on an average error of 6.79\%. Copyright (C) 2019 BCREC Group. All rights reserved
\end{abstract}

Keywords: Saponin; Sapindus rarak DC; Ultrasound-assisted extraction; Extraction kinetics study

How to Cite: Nafiunisa, A., Aryanti, N., Wardhani, D.H. (2019). Kinetic Study of Saponin Extraction from Sapindus rarak DC by Ultrasound-Assisted Extraction Methods. Bulletin of Chemical Reaction Engineering \& Catalysis, 14(2): 468-477 (doi:10.9767/bcrec.14.2.4253.468-477)

Permalink/DOI: https://doi.org/10.9767/bcrec.14.2.4253.468-477

\section{Introduction}

Saponins belong to a various group of naturally occurring surface-active compounds. It is known as a plant-derived natural surfactant. The saponaceous substances can form soap-like foams or lathers in water solution because of its hydrophobic and hydrophilic molecular structure [1]. In general, saponin is an amphiphilic

* Corresponding Author.

E-mail: nita.aryanti@che.undip.ac.id (N. Aryanti) glycoconjugate with a triterpenoidal or steroidal hydrophobic backbone and one or two hydrophilic glycoside moieties attached to the backbone [2]. A combination of the nonpolar sapogenin and the polar chain of saponin is very similar to the structure of most synthetic surfactants, having lipophilic and hydrophilic molecular parts [3]. Considering this characteristic, saponin has great potential to alternate synthetic surfactants. This kind of natural surfactant is easily degradable in nature, shows low 
toxicity, and has similar characteristics to synthetic surfactants.

Saponin can be found in various parts of plant tissues including fruits, flowers, roots, seeds, and shoots. Saponin is predominant in angiosperms plants and also occurs in some ferns, such as the Polypodium and Cyclamen species. Some algae and certain lower marine organisms are also found to be saponin sources. In the Asia region, the sapindaceae species is one of the main sources of saponin. The sapindaceae species is widely distributed in all tropical and subtropical regions of Asia [4]. The most commonly found sapindaceae plant in Indonesia is Sapindus rarak DC. (de candole), which contains rich saponin on its fruit pericarps. Saponin has a surfactant characteristic and shows the activity of molluscum, antiinflammatory, cytotoxic, and anti-platelet aggregation [5-6]. Saponin is commonly used as a detergent or emulsifying agent in cleansers, shampoos, and cosmetics.

Because of saponin's importance, the extraction of saponin has been widely studied. Ultrasound-assisted extraction (UAE) is one of the non-conventional and green technologies for the extraction of bioactive compounds from plant materials. This extraction method can significantly reduce energy consumption and needs shorter extraction times. UAE is also known as an environmentally friendly and efficient way to extract natural bioactive compounds from plant tissues because of the low solvent consumption [7-8]. Both direct and indirect ultrasonic waves have been applied to the extraction of saponins from different varieties of ginseng roots. UAE methods have also been conducted to extract saponin from various plant sources, such as: Panax notogingseng, soybean, chickpea, Allium nigrum L., and T. terrestris [9].

The extraction operating parameters are crucial to finding an effective extraction process with high yield and purity. These parameters are closely related to the extraction of kinetic parameters. Determining the kinetic parameters is very important in describing the mechanism that drives the extraction process to produce certain compounds from various materials. The experimental data are analyzed using empirical and physical models based on the solid-liquid processes [10]. This data was then presented in simpler mathematical kinetic models. The model can be used to predict the extraction rate and the stationary times required to complete the extraction process, which is a basic data for the scaling-up process. For that reason, the extraction kinetics param- eter is essential to allow their adequate use in industrial scale. The data from kinetic studies are needed to design the production equipment such as reactor or extractor. Moreover, the kinetic model also improves the procedure precision, minimizing processing errors and increasing the final quality of the product [11-12].

The previous study of extraction kinetics had been conducted to extract the phenolic compound from grape pomace [13], oleanolic acids from Hedyotis diffusa [14], polyphenol from abies bark [10], and anthocyanin from roselle calyces [15] and black chokeberry [11]. However, there are few studies of extraction kinetics for saponin from Sapindus rarak DC. To our best knowledge, few studies have explained the saponin extraction kinetics, such as kinetic studies of saponin leaching from quinoa seed $[12,16]$ and kinetic studies of saponin extraction from Saponaria vaccaria $L$. seeds [17]. The previous kinetic studies were focused on the leaching mechanism to obtain saponin, where the raw materials were only soaked for a specific time in a solvent. The model was mainly based on Fick's second law of diffusion. However, this model is not appropriate for the case of UAE [11], where the materials are irregular in size, showing a form of particles swelling, and the mass transfer is affected by the additional force from the ultrasonic waves.

Consequently, this work performs a scarce kinetic study for UAE of saponin from the pericarps of Sapindus rarak DC. The main objective is to investigate the extraction process of saponin from the pericarps of Sapindus rarak $D C$. Specifically, the kinetic models could be applied to achieve high-performance extraction. The effect of the solvent and solute ratios as well as the effect of temperature on the yield of saponin extract was observed at various extraction times. Associated with the extraction kinetic study of UAE for saponin, four different models are used to investigate the most suitable equation to describe the extraction process.

\section{Materials and Method}

\subsection{Materials}

The raw pericarps of Sapindus rarak $D C$ were purchased from Sleman, Yogyakarta, Indonesia. Distilled water, as a solvent, was obtained from the Laboratory of MeR-C, UPT, Undip, Indonesia. Pure saponin (99\% saponin) was procured from Sigma Aldrich as the comparative standard. Before extraction, the pericarps of Sapindus rarak DC was dried using an oven at $100 \pm 2{ }^{\circ} \mathrm{C}$ under normal aeration 
conditions for an hour. The dried Sapindus rarak $D c$ was then crushed in a Miyako BL-151 PF-AP dry grinder. The powder was sieved through a 100 -mesh sieve to obtain a homogeneous fine powder of Sapindus rarak. The ready-to-use dry-grounded powder was stored in vacuum storage at a temperature of $7^{\circ} \mathrm{C}$, and silica gel was added to the vacuum storage container to keep the powder dry.

\subsection{Extraction Process}

UAE was performed in an ultrasonic bath device (Krisbow Bath Ultrasonic) with a constant power of $280 \mathrm{~W}$ at a frequency of $40 \mathrm{kHz}$. The ultrasonic bath device was equipped with digital sonication time and temperature control system. The dry Sapindus rarak powder with various solid-to-liquid (S/L) ratios (1:25, 1:50, $1: 70,1: 85,1: 100(\mathrm{w} / \mathrm{v}))$ was placed in a capped glass bottle and mixed with the solvent, distilled water. The bottle with suspension was sonicated for 2 hours in the ultrasonic device containing 4 liters of water at various temperatures $\left(30,40,50\right.$, and $\left.60^{\circ} \mathrm{C}\right)$. In each extraction batch, all samples were placed in the center of the ultrasonic bath at a depth of fifteen centimeters. To ensure each sample was sonicated equally, each sample was kept in the same position. After sonication, the solution was filtered using filter cloth and centrifuged at 4.500 rpm for 15 minutes to separate out the solid particles. The supernatant was carefully collected for further analysis.

\subsection{Determination of Saponin Content}

The determination of saponin content was conducted by UV light scatter spectrophotomet-

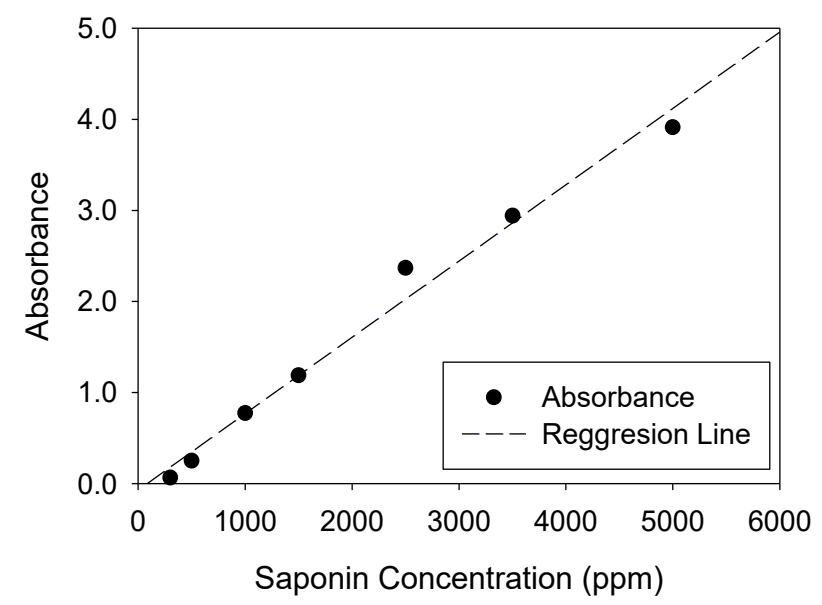

Figure 1. The spectroscopic absorbance of pure saponin at various concentrations (used as calibration curve) ric analysis using a UV-Visible spectrophotometer (Shimadzu UV mini 1240) [9,18]. Pure saponin purchased from Sigma Aldrich was used as the standard solution reference to make the calibration curves. The calibration curve was prepared by analyzing the absorbance of pure saponin solution at various concentrations (300-500 ppm). Spectrophotometric analysis was performed by measuring the absorbance at the maximum absorption wavelength $(312 \mathrm{~nm})$ using reagent blank as reference. The linear regression equation of the standard curve was made based on the concentrations $(x)$ versus the absorbance value $(y)$, Equation (1), with the obtained $R^{2}$ of 0.983 . The calibration curve is shown in Figure 1.

$$
y=0.0008 x-0.0707
$$

2.4 Statistical Analysis for Kinetic Modeling Extractions

The extraction of saponin was investigated at 30,40 , and $50{ }^{\circ} \mathrm{C}$ for $5,10,20,40,80$, and $120 \mathrm{~min}$, respectively, under the maximized $\mathrm{S} / \mathrm{L}$ ratio determined from the previous section. Experimental data (milligrams saponin per gram of dry feed) as a function of time were fitted to the four kinetic models presented in Table 1 . The statistical analysis of the data was performed using the generalized reduced gradient non-linear algorithm with the help of a solver engine from Microsoft Excel 2013 MSO 32-bit (Microsoft Office Professional Plus 2013, USA). In the equations, $C_{0}$ and $C$ represent the saponin extracted $(\mathrm{mg} / \mathrm{g})$ at time zero and time $t$ (in minutes), respectively, and $k$ (in minutes) is the extraction rate constant at a given temperature. Table 1 shows the mathematical equations used in a previous study of extraction kinetics.

The fitted model was evaluated by considering the statistical criteria. The coefficient of determination $\left(r^{2}\right)$ and adjusted $R$-square ( $R^{2}$ adjusted $)$ were the evaluated by statistical criteria [10,21]. The $r^{2}$ and $R^{2}$ adjusted are calculated by Equations (6) and (9), respectively.

$$
\begin{aligned}
& r^{2}=1-\frac{\sum_{i=1}^{n}\left(y_{i}-\hat{y}_{i}\right)^{2}}{\sum_{i=1}^{n}\left(y_{i}-\bar{y}_{i}\right)^{2}} \\
& S S T=\sum_{i=1}^{n}\left(a_{\text {measured }}-\bar{a}_{\text {measured }}\right)^{2} \\
& S S E=\sum_{i=1}^{n}\left(a_{\text {measured }}-a_{\text {predicted }}\right)^{2}
\end{aligned}
$$




$$
R_{\text {adjusted }}^{2}=1-\left[\left(\frac{n-1}{n-k-1}\right) x \frac{S S E}{S S T}\right]
$$

Where $n$ is the number of observations, $k$ is the number of parameter, $y_{\mathrm{i}}$ is the actual experimental yield of the $i^{\text {th }}$ sample, $\hat{y}_{i}$ is the modelfitting data of the $i^{\text {th }}$ sample, $\bar{y}_{\mathrm{i}}$ is the mean value of all experimental data, and $i$ is the sample number. Meanwhile, $a_{\text {measured }}$ is the value of saponin concentration obtained from the experiments, $a_{\text {predicted }}$ is the value of calculated saponin concentration based on the model, and $\bar{a}_{\text {measured }}$ is the mean of all measured saponin concentration. The $r^{2}$ value is calculated to be between 0 and 1 . The model with higher $r^{2}$ and $R^{2}$ adjusted for saponin extraction is considered the best choice for modeling the saponin extraction behavior during processing [21-22].

\subsection{Data Analysis}

All experiments were conducted in triplicate to diminish experimental errors. Results were expressed as a mean \pm standard deviation for $\mathrm{n}=3$. The data were graphically plotted using Microsoft Excel 2007, representing the average of at least three measurements with a relative standard deviation lower than $5 \%$.

\section{Results and Discussion}

UAE of saponin from the pericarps of Sapindus rarak $D C$ was studied under various conditions. In this study, the experimental design focused on two main extraction parameters: temperature and S/L ratio (weight/volume). Distilled water is used as a solvent on the extraction, and a green method of extraction was conducted with the assistance of ultrasonic waves. The extraction using ultrasonic-assisted is

Table 1. Kinetic models for extraction of compounds from plant matrices

\begin{tabular}{|c|c|c|}
\hline Equation & Model & Refs. \\
\hline$(2)$ & $C=\frac{C_{s}^{2} \cdot k \cdot t}{1+C_{s} \cdot k \cdot t}$ & [10] \\
\hline (3) & $C=C_{s}-\frac{C_{s}}{\exp (k . t)}$ & {$[19]$} \\
\hline (4) & $C=\frac{t}{K_{1}}+K_{2} \cdot t$ & [11] \\
\hline (5) $\mathrm{C}$ & $C=A[1-\exp (-B . t)]+C[1-\exp (-D . t)]$ & {$[20]$} \\
\hline
\end{tabular}

widely used to extract various substances from natural sources. Some experiment proved that using ultrasonic waves for extracting natural substance from plants provided more benefits than other methods, such as when extracting anthocyanin from blackberry and sweet cherry cultivar [23], polyphenol from Picea abies bark [10], antioxidants from Jatropha integerrima [24], and saponin from Allium nigrum L. [25]. UAE and conventional maceration extraction results were also compared by Aryanti et al. [26] for extracting anthocyanin from red and purple roselle calyces. The research proved that extraction with the assistance of ultrasonic wave provides better results than conventional extraction by maceration. The extractions using UAE methods were giving anthocyanin concentrations about 16 times higher than extractions using ME. In this current study, the extraction of saponin from Sapindus rarak $D C$ are conducted and the results are presented in the following section.

\subsection{Influence of Solid-to-Liquid Ratio on Total} Saponin of the Extracts

The evolutions of extracted total saponin versus time, obtained at different operating conditions, are presented in Figure 2. The first investigation was conducted for various $\mathrm{S} / \mathrm{L}$ ratios, and the temperature was set for $30{ }^{\circ} \mathrm{C}$. It is important to optimize the $\mathrm{S} / \mathrm{L}$ ratio, as the excess solvent does not have a significant effect on extraction yield. Therefore, solvent is wasted, decreasing the throughput and increasing the vessel size, affecting the equipment design.

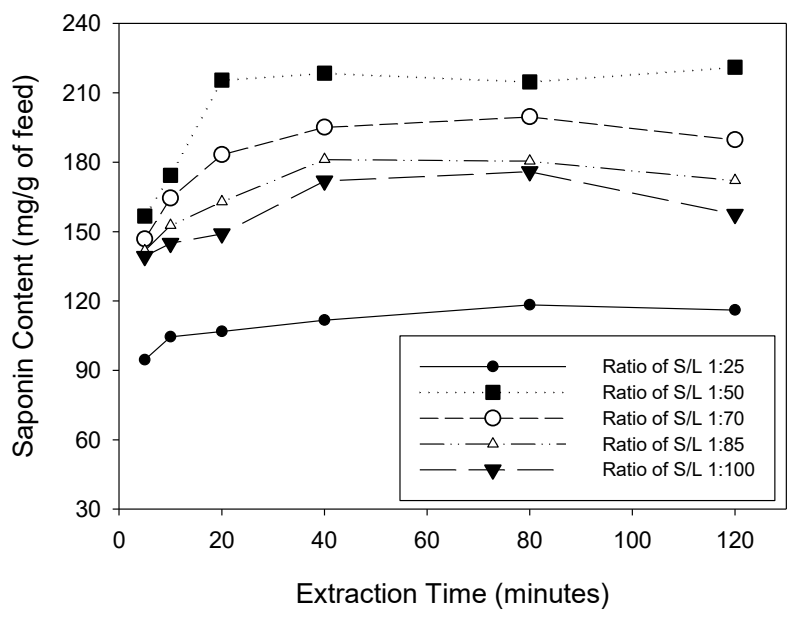

Figure 2. Effect of the solid-to-liquid (S/L) ratio on the extracted saponin on the ultrasoundassisted extraction of Sapindus rarak DC. Experimental conditions: Temperature $30{ }^{\circ} \mathrm{C}$ 
The saponin content was analyzed at specific times along the extraction process, which was performed for 120 minutes under the assistance of ultrasonic waves. The extraction of saponin shows an increase of saponin content by adding time. However, the saponin content remains stable after a specific time, showing that the extraction process reaches an equilibrium point where the solvents are saturated with the saponin compound. Moreover, performing an extraction process under ultrasonic waves for a long time destroys the saponin compound [27,28]. Consequently, an extraction for more than 120 minutes was not conducted in this study.

In the preliminary study, an S/L ratio less than 1:25 (w/v) was inadequate to disperse the dry pericarps powder of Sapindus rarak $D C$ properly. Hence, the lowest S/L ratio used in this study was 1:25. The lowest saponin content was observed at the ratio of $1: 25$, showing that the solvent amount was not enough to solubilize all the saponin from the plant material. Increasing the $\mathrm{S} / \mathrm{L}$ ratio to $1: 50(\mathrm{w} / \mathrm{v})$ shows a higher saponin content of $234 \mathrm{mg} / \mathrm{g}$ solid feed. However, increasing the S/L ratio to 1:70, 1:85, and 1:100 (w/v) provided less saponin content. Therefore, the maximum amount of extracted saponin was obtained at an S/L ratio of 1:50 $(\mathrm{w} / \mathrm{v})$.

A higher S/L ratio allows for homogenous mixing and allows for penetration of the solvent into deep interior parts. This effect implies a greater concentration gradient between the interior plant cells and the solvent and that the transfer of saponin from the solid to the solvent is enhanced [29]. As shown in Figure 1, the increase of extracted saponin content by increasing the $\mathrm{S} / \mathrm{L}$ ratio corresponds to the following mass transfer principles. The driving force during mass transfer within the solid is the concentration gradient. The concentration of saponin inside the plant materials is greater than the saponin concentration in the solvent, inducing the transfer of the saponin compound from the high-concentration regions to lowconcentration regions [30]. The extracted saponin content increases when a higher amount of solvent was used in the extraction process. However, at some point, adding additional solvent did not give any significant difference to the total extracted saponin. This phenomenon shows that no more saponin can be transferred to the solvent.

In addition, the highest saponin content was achieved at an $\mathrm{S} / \mathrm{L}$ ratio of $1: 50(\mathrm{w} / \mathrm{v})$. The amount of extracted saponin content also is affected by the extraction conditions, such as the modifications of solubility and the interactions of solute with solvent. The solubility of the saponin compound is affected by changes in the activity coefficient, which varies with the temperature and composition of the solution [20]. Interactions of the compounds with the solvent could also have modified the activity coefficients and thus the solubility of the compounds. In summary, the main effect of the S/L ratio was to modify the solubility and equilibrium constants and thus increase the total saponin concentration to a maximum at the highest $\mathrm{S} / \mathrm{L}$ ratio. Thus, the optimum $\mathrm{S} / \mathrm{L}$ ratio of $1: 50$ g. $\mathrm{mL}^{-1}$ was finalized for subsequent studies.

3.2 Influence of Temperature Condition on Total Saponin of the Extracts

A second investigation was conducted for various temperature conditions with an $\mathrm{S} / \mathrm{L}$ ratio of $1: 50(\mathrm{~g} / \mathrm{mL})$. The results of saponin extraction under four temperature conditions are shown in Figure 3. The figure shows the positive effects of temperature on saponin concentration, as the saponin content at $50{ }^{\circ} \mathrm{C}$ is $50 \%$ greater than that at $30{ }^{\circ} \mathrm{C}$. In this study, the extraction yield kept increasing as the temperature increased. The highest saponin concentration was achieved at $50{ }^{\circ} \mathrm{C}$, with a concentration of $354.92 \mathrm{mg} / \mathrm{g}$. In the process of natural compound extraction, temperature highly affected the result.

Previous studies reported that increased temperature increases the extraction rates of natural compounds. At higher temperatures, the solubility of the extracted compounds was increased because of its decreased viscosity, improving the mass transfer and accelerating

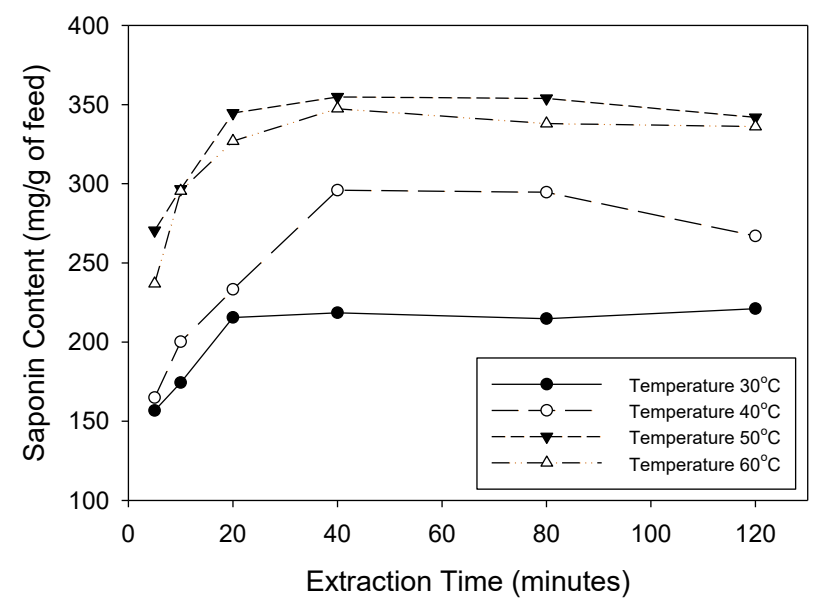

Figure 3. Effect of temperature on the extracted saponin on the UAE of Sapindus rarak DC. Experimental conditions: S/L ratio of $1: 50(\mathrm{~g} / \mathrm{mL})$ 
the extraction process. Similar results were found in the hot extraction of the phenolic compound from spruce bark [10].

Theoretically, temperature affects the mass transfer rate and the solubility of some compounds in the extraction process [31]. Increasing the temperature can help determine the efficient extraction condition from the interior parts. In the extraction process, the ultrasonic waves help the extraction process by creating micro-cavitation bubbles in the liquid outside the plant materials. When the micro-cavitation bubbles collapse, they activate locally mechanical disruption and heating on the plant cell wall, releasing the plant compounds [7]. As the temperature increases, more bubbles are formed. More bubble formation helps cell disruption, improves energy distribution, and increases the collapse intensity around the plant materials. Higher temperature also helps the extraction by decreasing the surface tension, making the compound inside the plant tissue more easily diffuse out, resulting in greater cell disruption and increasing mass transfer [32].

However, the saponin content slightly decreased as the temperature increased to $60{ }^{\circ} \mathrm{C}$. The most common cause is the heat-sensitive molecular structure of the natural compound. In the ultrasonic-assisted process, the phenomena were also affected by the decreased cavitation, increased vapor pressure, and decreased surface tension within microbubbles, causing the damping of ultrasonic waves [31-33]. The exposure of ultrasonic waves at high temperature for a long period may also cause a destructive effect on the natural compound such as saponin. The previous studies show that most natural compounds can not withstand high temperature. For example, anthocyanin from Roselle was verified to visibly degrade at a temperature of $60^{\circ} \mathrm{C}$ [33]. The extraction of camptothecin from Nothapodytes nimmoniana plant assisted with ultrasonic also shows a negative effect beyond $50{ }^{\circ} \mathrm{C}$ and a slight decline from 30 ${ }^{\circ} \mathrm{C}$ to $40{ }^{\circ} \mathrm{C}$ [31]. By considering the theoretically negative result caused by adding too much heat and long exposure of ultrasonic waves, 50 ${ }^{\circ} \mathrm{C}$ was finalized as the maximum temperature.

\subsection{Kinetic Study of Saponin Extraction}

In the solid-liquid extraction context, temperature and $\mathrm{S} / \mathrm{L}$ ratio are important variables to determine the better extraction performance. Therefore, the conditions of temperature and $\mathrm{S} / \mathrm{L}$ ratio were evaluated to determine the better condition where higher yield was achieved. Mathematical models consisting equations that provide an output based on a set of input data can be considered a concise way to express physical behavior. Various phenomena might govern the removal of compounds from plant matrices, including sorption/desorption, washing, and swelling of plant material, and diffusion. Choosing the best mathematical model to represent processing curves is fundamental to minimize processing errors, maximize final product quality, and facilitate the design and simulation of industrial processes. The maximum condition giving the highest yield of saponin based on the previous section is at a ratio $\mathrm{S} / \mathrm{L}$ of 1:50 and an extraction temperature of 50 ${ }^{\circ} \mathrm{C}$. The experimental data (milligrams saponin per gram of dry feed) from the maximized condition were fitted to kinetic models presented in Table 1 as a function of time.

The extraction was assisted with ultrasonic waves helping destroy the cell walls of the plant materials, allowing the saponin compound to easily solubilize in the water. The saponin molecular structure consists of hydrophobic and hydrophilic parts [7]. The hydrophilic structure of saponin is a sugar chain with high water affinity. The sugar mostly presents as a pyranose sugar with many hydroxyl groups (-OH) attached to it [3]. The hydrogen group easily forms a hydrogen bond with water molecules $(\mathrm{H}-\mathrm{O}-\mathrm{H})$ in the water solution. This formation of hydrogen bonds with water molecules allows saponin to be easily extracted to the water solvent. The interaction between the saponin molecules and the water molecules in the water solution is illustrated in Figure 4.

The mathematical model is used to predict the UAE process mechanism. The second-order kinetics model equation (Equation 2) compares the extracted compounds based on time. Here, $C_{\mathrm{s}}$ is the concentration of total polyphenols at saturation in the liquid extraction $(\mathrm{mg} / \mathrm{L})$, and $\mathrm{k}$ is the second-order extraction rate constant (L/g.min) [10]. A pseudo-first-order model (Equation 3) considers that the compound con-

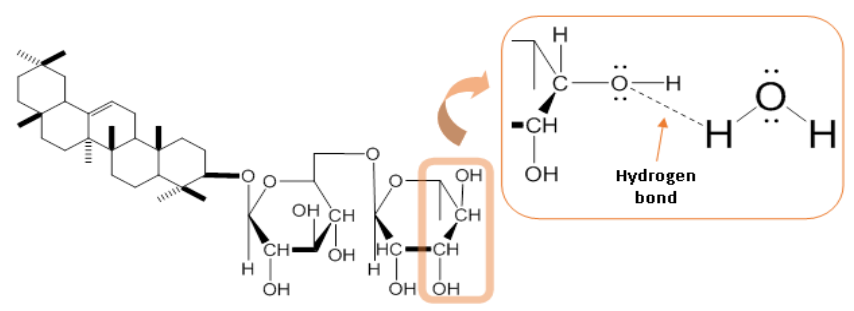

Figure 4. Schematic illustration of the interaction between the saponin and water molecules in the water solution 
centration in the extract tends to plateau [19]. Equation 4 is based on the sorption/desorption mechanism to remove compounds from the plant material [11]; in the model, $\mathrm{K}_{1}$ represents the extraction rate constant and $\mathrm{K}_{2}$ represents Peleg's capacity constant. Equation 5 assumes that the compounds are extracted in two distinct periods that are related to accessible and inaccessible compounds (outside and inside the plant cells, respectively) [20]. The B and D parameters are the extraction rates of the two different classes of compounds, $\mathrm{A}$ and $\mathrm{C}$ are constants.

Extraction kinetics is usually expressed in terms of solute concentration extracted from the solid to the solvent per unit time [34]. The mechanism of extraction of natural compounds from plant matrices is not fully enlightened; therefore, several mathematical equations have been described in the literature. Statistical errors for fitting the experimental data of extraction of saponin from Sapindus rarak $D C$ to models used in previous publications are shown in Table 2.

Analyzing the data presented in Table 2 shows that the best model to describe the extraction of saponin from the pericarps of Sapindus rarak $D C$ is the second-order kinetics model (Equation 2) because the model shows the highest $\mathrm{r}^{2}$ values, and $\mathrm{R}^{2}$ adjusted. The secondorder kinetics model shows that the saponin extraction on the studied conditions is continuous. Therefore, the practical calculation based on the second-order kinetic models is discussed in the next section for the extraction process at an $\mathrm{S} / \mathrm{L}$ ratio of $1: 50$, temperature of $50{ }^{\circ} \mathrm{C}$, and various extraction times.

\subsection{The Practical Calculation Based on the} Second-Order Kinetic Model

The experimental data of the UAE extraction were processed and plotted in the specific coordinates of the second-order kinetic model.

Table 2. Summary of fitting model parameter of selected models to describe the extraction of saponin from Sapindus rarak $D C$

\begin{tabular}{clll}
\hline No & Equation & $r^{2}$ & $R^{2}$ adjusted \\
\hline 1 & $\begin{array}{l}\text { Second-order kinetics } \\
\text { model (Equation 2) }\end{array}$ & 0.929 & 0.892 \\
2 & $\begin{array}{l}\text { Pseudo first-order model } \\
\text { (Equation 3) }\end{array}$ & 0.829 & 0.795 \\
3 & $\begin{array}{l}\text { Modified Pelleg's model } \\
\text { (Equation 4) }\end{array}$ & 0.887 & 0.852 \\
4 & $\begin{array}{l}\text { Two-step transfer model } \\
\text { (Equation 5) }\end{array}$ & 0.829 & 0.791 \\
\hline
\end{tabular}

The dissolution rate of saponin contained in the solid can be described by the second-order kinetic model presented in Equation (10) [15]:

$$
\frac{d C_{t}}{d t}=k\left(C_{s}-C_{t}\right)^{2}
$$

Here, $C_{\mathrm{t}}$ is the concentration of total polyphenols in the liquid extraction $(\mathrm{mg} / \mathrm{L})$ at a given extraction time $t$ (min), $C_{\mathrm{s}}$ is the concentration of total polyphenols at saturation in the liquid extraction $(\mathrm{mg} / \mathrm{L})$, and $k$ is the second-order extraction rate constant (L/g.min). To determine the kinetic parameters, Equation (10) is integrated under the boundary conditions $C_{\mathrm{t}}=0$ to $C_{\mathrm{t}}$ and $t=0$ to $t$. The equation was then linearized in the form of Equation (11), where $h$ is the initial extraction rate (g/L.min) when $t$ and $C_{\mathrm{t}}$ approach 0 [15]:

$$
\frac{t}{C_{t}}=\frac{1}{k \cdot C_{s}^{2}}+\frac{t}{C_{s}}=\frac{1}{h}+\frac{t}{C_{s}}
$$

Figure 5 presents the experimental data showing a linear line after the plot of equation models. Table 3 presents the kinetic parameter for the second-order kinetics model. The specific kinetic parameters, such as: extraction

Table 3. Kinetic parameters for the second-order

\begin{tabular}{|c|c|c|c|c|}
\hline $\begin{array}{c}T \\
\left({ }^{\circ} \mathrm{C}\right)\end{array}$ & $\begin{array}{c}h \\
\left(\mathrm{mg}^{-L^{-1}} \cdot \mathrm{min}^{-1}\right)\end{array}$ & $\begin{array}{c}k \\
\left(\mathrm{~L} . \mathrm{mg}^{-1} \cdot \mathrm{min}^{-1}\right)\end{array}$ & $\begin{array}{c}C_{\mathrm{s}} \\
\left(\mathrm{mg} \cdot \mathrm{L}^{-1}\right)\end{array}$ & $R^{2}$ \\
\hline 30 & 74.63 & 0.00138 & 232.56 & 0.9972 \\
\hline 40 & 126.58 & 0.00155 & 285.71 & 0.9925 \\
\hline 50 & 588.24 & 0.00495 & 344.83 & 0.9988 \\
\hline 60 & 312.5 & 0.00263 & 344.83 & 0.9959 \\
\hline
\end{tabular}
kinetic model

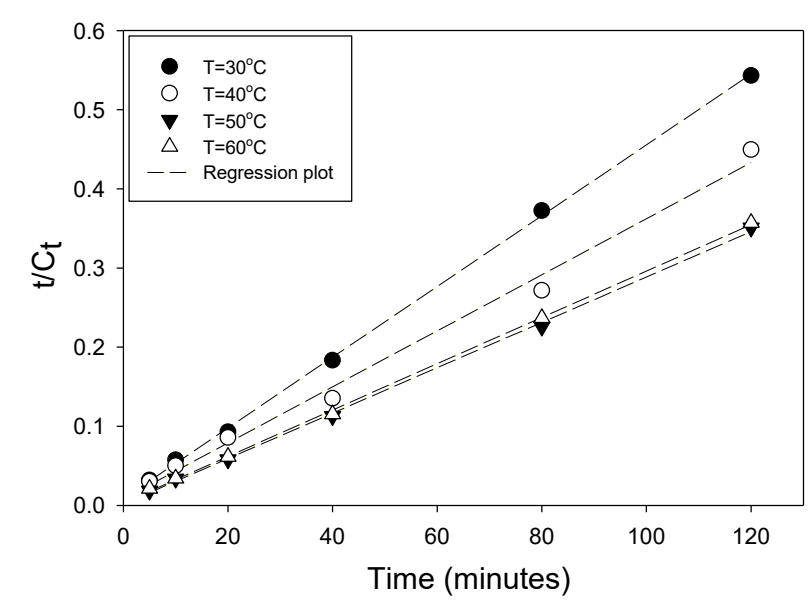

Figure 5. Validation of the second-order kinetics model 
capacity (concentration at saturation - $C_{\mathrm{s}}$ ), extraction rate constant $(k)$, and initial extraction rate $(h)$ were determined based on the mathematical regression equations for each temperature. They can be determined experimentally from the slope and intercept of plotting $t / C_{\mathrm{t}}$ against $t$. The fitting of the second-order kinetic model for all experimental data is confirmed by the value of the mathematical regression coefficient $\left(\mathrm{R}^{2}>0.99\right)$.

The second-order kinetic model was also used to describe the release kinetics of total phenolics from oak chips into a model wine under ultrasounds action into a bath system [35]. In the kinetic modelling study of UAE of oil from pomegranate seeds using hexane as the solvent, reported that the best fits were given when the second-order law was applied [36]. The second-order model also was used to describe the solid-liquid extraction processes of antioxidants from pomegranate marc while stirring and using water as a solvent. The results show that the extraction rate constant $(k)$ increased as the temperature rises. Changes in $k$ values and other kinetic parameters show that the temperature change has a strong effect on the kinetic parameter. The plotting of the experimental result versus practical calculation using the obtained model also gives good comparison by an average error of $6.79 \%$, as shown in Figure 6.

\section{Conclusions}

In the present study, the investigation of saponin extraction from the pericarps of Sapindus rarak $D C$ and its extraction kinetics was conducted. The kinetic study of the UAE of saponin was performed to elucidate the phenome-

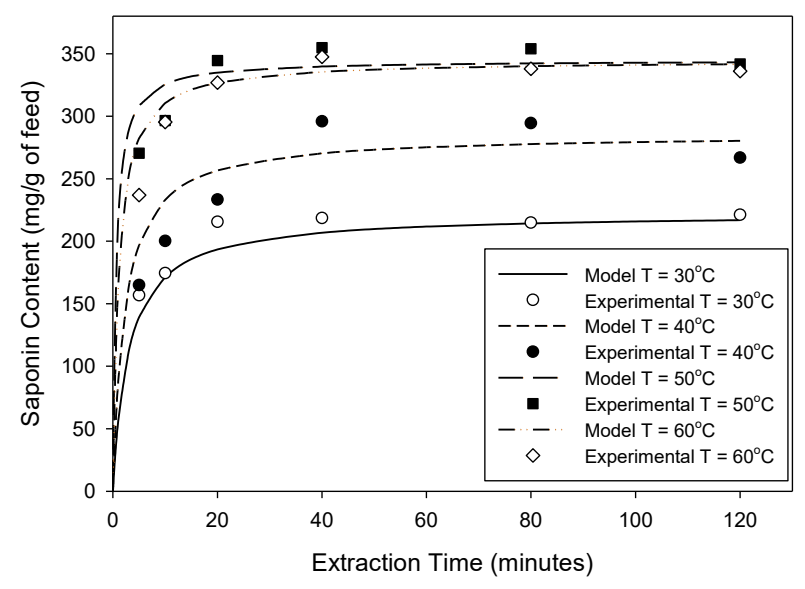

Figure 6. The comparison of experimental data with the practical calculation based on the second-order kinetic model na involved in this kind of process. The results show that the extraction condition had better performance was the extraction using an S/L ratio of $1: 50(\mathrm{w} / \mathrm{v})$ at $50{ }^{\circ} \mathrm{C}$. The kinetics study had shown that the second-order kinetics model can better describe the UAE process, with an $\mathrm{R}^{2}$ value of 0.929 and a rate coefficient of $0.00495 \mathrm{~L} . \mathrm{g}^{-1} \cdot \mathrm{min}^{-1}$. The highest yield achieved in this process was $354.92 \mathrm{mg}$ of saponin per gram of dried-ground pericarps of Sapindus rarak $D C$. The comparison of experimental results and practical calculations using the obtained model also gives good comparison by an average error of $6.79 \%$. The saponin from Sapindus rarak $D C$ was successfully extracted and is a cheap alternative of synthetic surfactant for industrial applications. The kinetics information of saponin extraction from plant resources supports industrial applications such as elucidating the phenomena and better equipment dimensioning. Where the rate coefficient is sufficient to be used in calculating the residence time in the extractor and determine the dimension of the extractor, a further comprehensive study is inevitably necessary.

\section{Acknowledgments}

The author would like to thank Diponegoro University for providing the financial support for this study. The research project was funded by the International Publication Research PNBP research grant of Diponegoro University year of 2018 with grant number 385100/UN7.P4.3/PP/2018.

\section{References}

[1] Roy D., Kommalapati, R.R., Mandava, S.S., Valsaraj, K.T., Constant, W.D. (1997). Soil Washing Potential of a Natural Surfactant. Environmental Science and Technology, 31: 670-675

[2] Arslan, I., Celik, A., Melzig, M.F. (2013). Nebulosides A-B, Novel Triterpene Saponins from Under-Ground Parts of Gypsophila Arrostii Guss. Var. Nebulosa. Bioorganic \& Medicinal Chemistry, 21: 1279-1283

[3] Oleszek, W., Arafa H. (2009). Saponin-Based Surfactants. Surfactants from Renewable Resources: John Wiley \& Sons, Ltd.

[4] Li, R., Wu, Z.L., Wang, Y.J., Li, L.L. (2013). Separation of total saponins from the pericarp of Sapindus mukorossi Gaerten by foam fractionation. Industrial Crops and Products, 51: 163-170.

[5] Huang, H.C., Tsai, W.J., Liaw, C.C., Wu, S.H., Wu, Y.C., Kuo, Y.H. (2007). AntiPlatelet Aggregation Triterpene Saponins 
from the Galls of Sapindus Mukorossi. Chemical Pharmacist Bulletin, 55: 1412-1415.

[6] Huang, H.C., Wu, M.D., Tsai, W.J., Liao, S.C., Liaw, C.C., Hsu, L.C., Wu, Y.C., Kuo, Y.H. (2008). Triterpenoid Saponins from the Fruits and Galls of Sapindus Mukorossi. Phytochemistry, 69: 1609-1616.

[7] Alupului, A., Calinescu, I., Lavric, V. (2009). Ultrasonic vs. Microwave Extraction Intensification of Active Principles from Medicinal Plants. Chemical Engineering Transactions, 17: 1023-1028.

[8] Majd, M.H., Rajaei, A., Bashi, D.S., Mortazavi, S.A., Bolourian, S. (2014). Optimization of Ultrasonic-Assisted Extraction of Phenolic Compounds from Bovine Pennyroyal (Phlomidoschema Parviflorum) Leaves Using Response Surface Methodology. Industrial Crops and Product, 57: 195-202.

[9] Cheok C.Y., Salman H.A.K., Sulaiman R. (2014). Extraction and Quantification of Saponins: A Review. Food Research International, 59: $16-40$.

[10] Lazar, L., Talmaciu, A. L., Volf, I., Popa, V. I. (2016). Kinetic modeling of the ultrasound assisted extraction of polyphenols from Picea abiesbark. Ultrasonics Sonochemistry, 32: 191-197.

[11] D’Alessandro, L.G., Dimitrov, K., Vauchel, P., Nikov, I. (2014). Kinetics of Ultrasound Assisted Extraction of Anthocyanins from Aronia Melanocarpa (Black Chokeberry) Wastes. Chemical Engineering Research and Design, 92: 1818-1826.

[12] Quispe-Fuentes, I., Vega-Gálvez, A., Miranda, M., Lemus-Mondaca, R., Lozano, M., Ah-Hen, K. (2012). A Kinetic Approach to Saponin Extraction during Washing of Quinoa (Chenopodium Quinoawilld.) Seeds. Journal of Food Process Engineering, 36: 202-210.

[13] González-Centeno, M.R., Comas-Serra, F., Femenia, A., Rosselló, C., Simal, S. (2015). Effect of Power Ultrasound Application on Aqueous Extraction of Phenolic Compounds and Antioxidant Capacity from Grape Pomace (Vitis Viniferal.): Experimental Kinetics and Modeling. Ultrasonics Sonochemistry, 22: 506-514.

[14] Wei, M.-C., Yang, Y.-C. (2014). Extraction Characteristics and Kinetic Studies of Oleanolic and Ursolic Acids from Hedyotis Diffusa under Ultrasound-Assisted Extraction Conditions. Separation and Purification Technology, 130: 182-192.

[15] Aryanti, N., Nafiunisa, A., Bella, N., Sanjaya, R., Wardhani, D.H., Kumoro, A.C. (2018). Kinetics of Ultrasound-Assisted Extraction of Anthocyanin from Purple Roselle Calyces un- der Different $\mathrm{pH}$ Conditions. Chemistry and Chemical Technology, 12 (4): 523-528.

[16] Irigoyen, R.M.T., Giner, S.A. (2018). Extraction Kinetics of Saponins from Quinoa Seed (Chenopodium quinoa Wild). International Journal of Food Studies, 7: 76-88.

[17] Shrestha, B.L., and Baik, O.D. (2012). Methanol-Water Extraction of Saponins From Seeds of Saponaria Vaccaria L. -Calibration Equation, Extraction Condition Analysis, and Modeling. Separation Science and Technology, 47: 1977-1984.

[18] Samal, K., Das, C., Mohanty, K. (2017). EcoFriendly Biosurfactant Saponin for the Solubilization of Cationic and Anionic Dyes in Aqueous System. Dyes and Pigments, 140: 100-108.

[19] Porto, C.D., Natoliono, A. (2018). Extraction Kinetic Modelling of Total Polyphenols and Total Anthocyanins from Saffron Floral BioResidues: Comparison of Extraction Methods. Food Chemistry, 258: 137-143.

[20] Cacace, J.E., Mazza, G. (2003). Mass Transfer Process during Extraction of Phenolic Compounds from Milled Berries. Journal of Food Engineering, 59: 379-389.

[21] Jianlong, W., Jaaman, S.H., Samsudin, H.B. (2015). R-Squared Measurement in Multifactor Pricing Model. AIP Conference Proceeding, 1678: 060001-1-060001-5.

[22] Sant'Anna, V., Utpott, M., Cladera-Olivera, F., Brandelli, A. (2010). Kinetic Modeling of Thermal Inactivation of Bacteriocin Like Inhibitory Substance P34. Journal of Agricultural and Food Chemistry, 58(5): 3147-3152.

[23] Oancea, S., Grosu, C., Ketney, O., Stoia, M. (2013). Conventional and UltrasoundAssisted Extraction of Anthocyanins from Blackberry and Sweet Cherry Cultivars. Acta Chimica Slovenica, 60(2): 383-389.

[24] Xu, D.P., Zhou, Y., Zheng, J., Li, S., Li, A.N., Li, H.B., (2015). Optimization of UltrasoundAssisted Extraction of Natural Antioxidants from the Flower of Jatropha integerrima by Response Surface Methodology. Molecules. 21(18): 1-12.

[25] Mostafa, A., Sudisha, J., El-Sayed, M., Ito, S.I., Ikeda, T., Yamauchi, N., Shigyo, M. (2013). Aginoside Saponin, a Potent Antifungal Compound, and Secondary Metabolite Analyses fromAllium nigrum L. Phytochemistry Letters, 6(2): 274-280.

[26] Aryanti, N., Nafiunisa, A., Wardhani, D.H. (2019). Conventional and UltrasoundAssisted Extraction of Anthocyanin from Red and Purple Roselle (Hibiscus sabdariffa L.) 
Calyces and Characterisation of Its Anthocyanin Powder. International Food Research Journal, 26(2): 529-535.

[27] Goula A.M. (2013). Ultrasound-Assisted Extraction of Pomegranate Seed Oil-Kinetic Modeling. Journal of Food Engineering, 117: 492-498.

[28] Zhang, W.-N., Zhang, H.-L., Lu, C.-Q., Luo, J.-P., Zha, X.-Q. (2016). A New Kinetic Model of Ultrasound-Assisted Extraction of Polysaccharides from Chinese chive. Food Chemistry, 212: 274-281.

[29] Vinatoru, M. (2001). An Overview of the Ultrasonically Assisted Extraction of Bioactive Principles from Herbs. Ultrasonic Sonochemistry, 8: 303-313.

[30] Ghassemi, M., Shahidian, A. (2017). Chapter 3 - Biosystems Heat and Mass Transfer. Nano and Bio Heat Transfer and Fluid Flow: Academic Press.

[31] Patil, D.M., Akamanchi, K.G. (2017). Ultrasound-Assisted Rapid Extraction and Kinetic Modelling of Influential Factors: Extraction of Camptothecin from Nothapodytes nimmoniana Plant. Ultrasonics Sonochemistry. 37: $582-591$.
[32] Shirsath S.R., Sonawane S.H., Gogate P.R. (2012). Intensification of Extraction of Natural Products Using Ultrasonic Irradiations-A Review of Current Status. Chemical Engineering and Processing: Process Intensification, 53: 10-23.

[33] Aurelio, D.-L., Edgardo, R.G., and NavarroGalindo, S. (2008). Thermal kinetic degradation of anthocyanins in a roselle (Hibiscus sabdariffaL. cv. 'Criollo') infusion, International Journal of Food Science and Technology, 43: 322-325.

[34] Allaf, K.S., Besombes, C., Berka, B., Kristiawan, M., Sobolik, V., Allaf, T.S.V. (2011). Instant Controlled Pressure Drop Technology in Plant Extraction Processes. In K. Allaf (Ed.), Enhancing extraction processes in the food industry (pp. 255-303). Dublin: CRC Press Taylor \& Francis Group.

[35] Tao Y., Zhang Z., Sun D.-W. (2014). Experimental and Modeling Studies of Ultrasound assisted Release of Phenolics from Oak Chips into Model Wine. Ultrasonic Sonochemistry, 21: 1839-1848.

[36] Qu, W., Pan, Z., Ma, H. (2010). Extraction Modeling and Activities of Antioxidants from Pomegranate Marc. Journal of Food Engineering, 99: 16-23.

Selected and Revised Papers from The $3^{\text {rd }}$ International Conference on Chemical and Material Engineering (ICCME) 2018 (http://iccme2018.undip.ac.id) (Diponegoro University, by 19th-20th September 2018) after Peer-reviewed by Scientific Committee of ICCME 2018 and Peer-Reviewers of Bulletin of Chemical Reaction Engineering \& Catalysis 